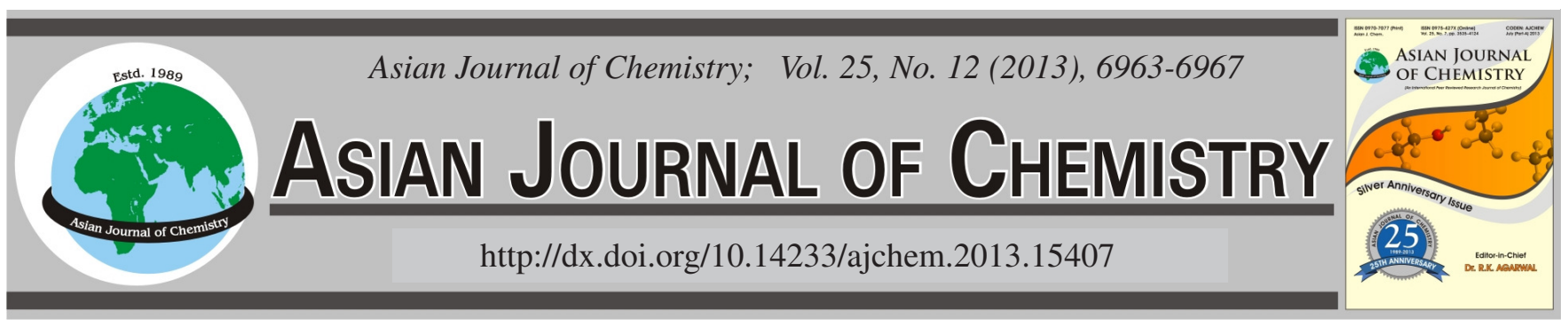

\title{
Electrospun $\mathrm{TiO}_{2}$ Microspheres with Enhanced Activity for Photocatalytic Degradation of Methylene Blue
}

\author{
Hong Zhang ${ }^{1, *}$, XinjuAn LiU ${ }^{2}$ and Zhuo Sun ${ }^{2}$
}

\begin{abstract}
${ }^{1}$ College of Electrical and Mechanical Engineering, Fujian Agriculture and Forestry University, Fuzhou 350002, Fujian Province, P.R. China ${ }^{2}$ Engineering Research Center for Nanophotonics \& Advanced Instrument, Ministry of Education, Department of Physics, East China Normal University, Shanghai 200062, P.R. China
\end{abstract}

*Corresponding author: Tel: +86 591 83757702; E-mail: zhanghong381@126.com

(Received: 2 March 2013;

Accepted: 7 June 2013)

AJC-13611

$\mathrm{TiO}_{2}$ microspheres were synthesized by electrospinning technique. The morphology, structure and photocatalytic performance in the
degradation of methylene blue under $\mathrm{UV}$ light irradiation were characterized by scanning electron microscopy, X-ray diffraction spectroscopy
and $\mathrm{UV}$-visible absorption spectrophotometer. The results show that $\mathrm{TiO}_{2}$ microspheres have a high anatase phase content and their
surface is assembled by large quantities of $\mathrm{TiO}_{2}$ nanoparticles, resulting in a porous structure. These $\mathrm{TiO}_{2}$ microspheres exhibit an
excellent photocatalytic performance with a maximum degradation rate of $95.6 \%$, much higher than that for $\mathrm{TiO}_{2}$ rods $(77.9 \%)$ synthesized
by electrospinning technique.
Key Words: $\mathrm{TiO}_{2}$, Electrospinning, Photocatalysis, Microsphere.

\section{INTRODUCTION}

Nowadays, $\mathrm{TiO}_{2}$ has attracted tremendous attention as a promising photocatalyst for widespread environmental applications owing to its intriguing optical and electric properties ${ }^{1-11}$. The photocatalytic performance of $\mathrm{TiO}_{2}$ is strongly affected by its crystal structure and morphology, which are determined by synthetic methods ${ }^{12,13}$. So far, numerous synthetic strategies such as sol-gel, hydrothermal, solvothermal, electrochemical anodization, electrodeposition and template assisted routes have been employed for the formation of $\mathrm{TiO}_{2}$ in the form of particles, tubes, fibers, wires, belts, rods, hollow spheres, microsphere, etc. ${ }^{14-28}$. Among various $\mathrm{TiO}_{2}$ structures, $\mathrm{TiO}_{2}$ microspheres with $\mathrm{TiO}_{2}$ nanoparticles assembled on the surface is a novel structure which show excellent photoactivity due to their large surface area and highly crystallized porous wall. Many studies on $\mathrm{TiO}_{2}$ microspheres have been reported recently. Naldoni et al. ${ }^{29}$ synthesized highly-crystalline porous $\mathrm{TiO}_{2}$ microspheres using ultrasonic spray pyrolysis in the presence of colloidal silica as a template and investigated their activity in the degradation of nitrogen oxides $\left(\mathrm{NO}_{\mathrm{x}}\right)$ in the gas phase. Liu et al. ${ }^{30}$ fabricated hollow mesoporous $\mathrm{TiO}_{2}$ microspheres by a sol-gel process, these microspheres exhibit excellent photocatalytic performance in the decomposition of methylene orange with a $90 \%$ degradation rate in $100 \mathrm{~min}$ under UV light irradiation. Dwivedi et al. ${ }^{31}$ reported mesoporous $\mathrm{TiO}_{2}$ microspheres synthesized by the sol-gel templating method for the degradation of methylene blue and about $70 \%$ of methylene blue (MB) was decomposed in 120 min under UV light irradiation.

The electrospinning technique is a well-established, simple, versatile, cost-effective and scalable means to produce different structured materials. Since its first patent describing the basic operation principle in 1934, this method was employed widely to fabricate various advanced materials including $\mathrm{TiO}_{2}{ }^{32-36}$. Recently, many studies have been reported to fabricate different $\mathrm{TiO}_{2}$ nanostructures by electrospinning method for photocatalytic application, such as multichannel hollow fibers ${ }^{37}$, mesoporous fibers ${ }^{38}$, rice grain-shaped $\mathrm{TiO}_{2}{ }^{39}$, nanowires ${ }^{40}$, nanotubes ${ }^{41-43}$ and network ${ }^{44}$. However, as promising photocatalyst, porous $\mathrm{TiO}_{2}$ microspheres with excellent photocatalytic activity fabricated by electrospinning method has seldom been reported up to now.

In this study, we fabricated $\mathrm{TiO}_{2}$ microspheres with nanoparticles assembled on the surface using electrospinning technique and investigated their photocatalytic performance in the degradation of methylene blue. These $\mathrm{TiO}_{2}$ microspheres exhibit excellent photocatalytic performance with a maximum methylene blue degradation rate of $95.6 \%$ under UV light irradiation. 


\section{EXPERIMENTAL}

Fabrication: The precursor solution was composed of $1 \mathrm{~g}$ PVP, $4.7 \mathrm{~g}$ titanium(IV) butoxide, a certain amount of urea ( $0 \mathrm{~g}$ and $0.237 \mathrm{~g}$, respectively) and $4 \mathrm{~mL}$ glacial acetic acid (Sinopharm Chemical Reagents Co. Ltd.) in $16 \mathrm{~mL}$ ethanol. After vigorous stirring at room temperature for $10 \mathrm{~h}$, the solution was then loaded into a syringe connected to a 22 gauge stainless steel needle. The applied voltage was $20 \mathrm{kV}$ and the distance from the tip of the needle to copper collector was 10 $\mathrm{cm}$. The flow rate of solution was $1 \mathrm{~mL} \mathrm{~h}^{-1}$. The electrospinning was carried out in enclosed plexiglass at room temperature at about $40 \%$ relative humidity. Then the samples were exposed to atmospheric moisture in ambient condition for $1 \mathrm{~h}$. The products were sintered at $500{ }^{\circ} \mathrm{C}$ in an air atmosphere for $0.5 \mathrm{~h}$. The $\mathrm{TiO}_{2}$ samples fabricated using precursor solution without urea and with urea were named as $\mathrm{TiO}_{2}-1$ and $\mathrm{TiO}_{2}-2$, respectively.

Characterization: The surface morphology, structure and composition of the samples were characterized by field-emission scanning electron microscopy (FESEM, Hitachi S-4800), X-ray diffraction spectroscopy (XRD, Holland Panalytical PRO PW3040/60) with $\mathrm{Cu}-\mathrm{K}_{\alpha}$ radiation $(\mathrm{V}=30 \mathrm{kV}, \mathrm{I}=25 \mathrm{~mA})$ and energy dispersive X-ray spectroscopy (EDS, JEM-2100), respectively. The UV-visible absorption spectra were recorded using a Hitachi U-3900 UV-visible spectrophotometer.

Photocatalytic experiments: The samples $\left(2 \mathrm{~g} \mathrm{~L}^{-1}\right)$ were dispersed in $80 \mathrm{~mL}$ methylene blue aqueous solutions $(5 \mathrm{mg}$ $\left.\mathrm{L}^{-1}\right)$. The mixed suspensions were first magnetically stirred in the dark for $0.5 \mathrm{~h}$ to reach the adsorption-desorption equilibrium. Under ambient conditions and stirring, the mixed suspensions were exposed to UV light irradiation produced by an $8 \mathrm{~W} \mathrm{UV}$ lamp $\left(\lambda_{\max }=254 \mathrm{~nm}\right)$. At certain time intervals, $2.5 \mathrm{~mL}$ of the mixed suspensions were extracted and all the aliquots withdrawn from the solutions were centrifuged to remove the photocatalyst. The filtrates were analyzed by recording UVvisible spectra of methylene blue using a Hitachi U-3900 UVvisible spectrophotometer.

The photocatalytic reaction kinetics was studied using Langmuir-Hinshelwood model. The pseudo-first-order equation is employed to fit the experimental data and can be formulated $\mathrm{as}^{45}$ :

$$
\ln \left(\mathrm{C}_{\mathrm{i}} / \mathrm{C}_{0}\right)=-\mathrm{kt}
$$

where $\mathrm{t}$ and $\mathrm{k}$ are the photocatalysis time ( $\mathrm{min}$ ) and the reaction rate constant $\left(\mathrm{min}^{-1}\right)$, respectively. $\mathrm{C}_{0}$ and $\mathrm{C}_{\mathrm{i}}$ are the initial concentration and the concentration of methylene blue at time $\mathrm{t}\left(\mathrm{mg} \mathrm{L}^{-1}\right)$, respectively.

\section{RESULTS AND DISCUSSION}

Fig. 1(a) and (b) show the FESEM images of $\mathrm{TiO}_{2}-1$ and $\mathrm{TiO}_{2}-2$. It is obvious that the morphology of $\mathrm{TiO}_{2}-2$ is different from that of $\mathrm{TiO}_{2}-1$. $\mathrm{TiO}_{2}-1$ consists of short rods and $\mathrm{TiO}_{2}-2$ displays porous microsphere structure. Fig. 1(c) is the highmagnification FESEM image of $\mathrm{TiO}_{2}-2$. It can be clearly observed that highly rough surface of microspheres is assembled by large quantities of nanosized $\mathrm{TiO}_{2}$ particles, resulting in a porous structure. Such a structure can facilitate the adsorption of more pollutants and thus improves the photocatalytic performance ${ }^{46}$. The existence of $\mathrm{TiO}_{2}$ in the both samples has been proved by the peaks of Ti and O in EDS data shown in Fig. 1(d) and the peak of $\mathrm{N}$ is not found. It indicates that the introduction of urea in the precursor solution does not alter the composition of $\mathrm{TiO}_{2}$ but changes its structure.

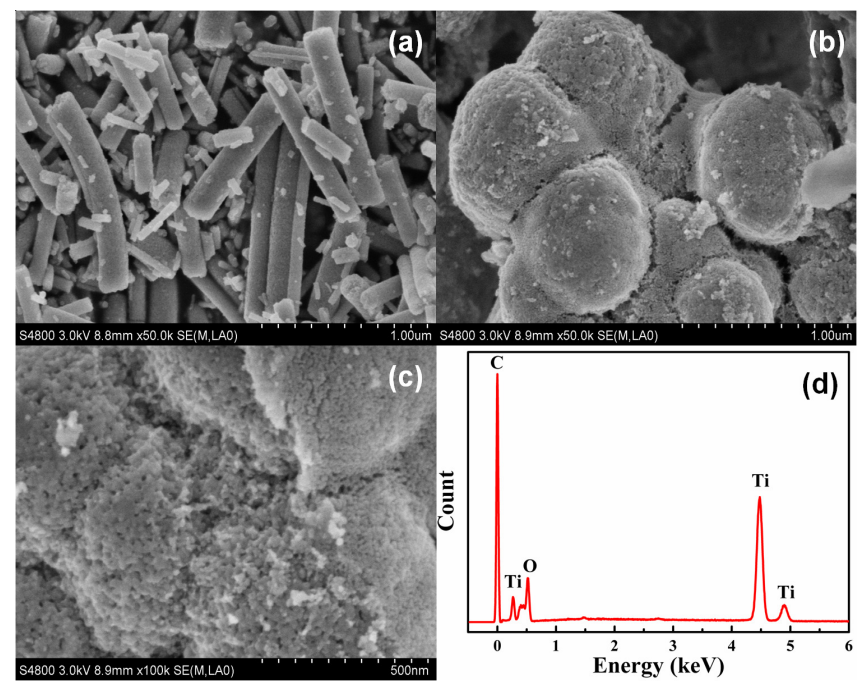

Fig. 1. Surface morphologies of (a) $\mathrm{TiO}_{2}-1$, (b) and (c) $\mathrm{TiO}_{2}-2$ by FESEM; (d) EDS spectrum of $\mathrm{TiO}_{2}-2\left(\mathrm{TiO}_{2}-1\right.$ has a similar EDS spectrum)

The XRD patterns of $\mathrm{TiO}_{2}-1$ and $\mathrm{TiO}_{2}-2$ are shown in Fig. 2. It can be observed that both samples exhibit several diffraction peaks at $25.3^{\circ}, 37.8^{\circ}, 48.0^{\circ}, 53.9^{\circ}, 55.1^{\circ}, 62.7^{\circ}, 68.8^{\circ}$, $70.3^{\circ}$ and $75.0^{\circ}$, which are indexed to (101), (004), (200), (105), (211), (204), (116), (220) and (215) crystal planes of anatase $\mathrm{TiO}_{2}$ (JCPDS\#21-1272), respectively. Three additional peaks at $27.4^{\circ}, 36.1^{\circ}$ and $41.2^{\circ}$ are assigned to (110), (101) and (111) crystal planes of rutile $\mathrm{TiO}_{2}$ (JCPDS\#77-0441), respectively. No typical diffraction peaks of nitrogen species are observed in the XRD pattern. Furthermore, it should be noticed that the diffraction peaks of rutile phase in $\mathrm{TiO}_{2}-2$ are weaker than those in $\mathrm{TiO}_{2}-1$ relative to anatase phase. Using the well-known formula, the anatase phase content in crystalline $\mathrm{TiO}_{2}$ powder is calculated ${ }^{47}$ :

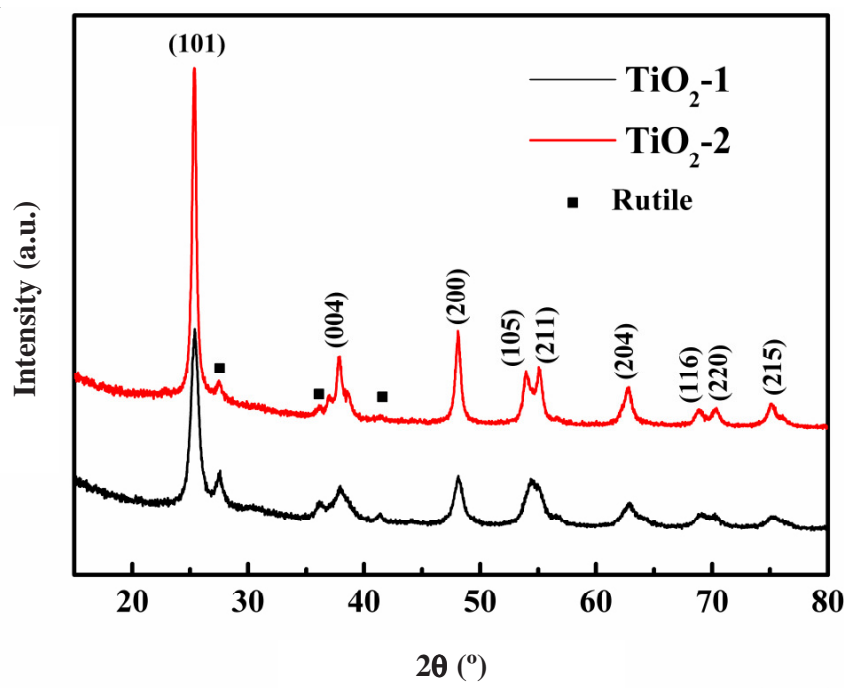

Fig. 2. XRD patterns of $\mathrm{TiO}_{2}-1$ and $\mathrm{TiO}_{2}-2$ 


$$
\mathrm{X}_{\mathrm{A}}=\left(1+1.265 \frac{\mathrm{I}_{\mathrm{R}}}{\mathrm{I}_{\mathrm{A}}}\right)^{-1}
$$

where $\mathrm{X}_{\mathrm{A}}$ is the mass fraction of anatase in the $\mathrm{TiO}_{2}$ powders and $I_{A}$ and $I_{R}$ are the integrated intensities of the (101) reflection of anatase and the (110) reflection of rutile, respectively. The calculation results are given in Table- 1 . It can be seen that the anatase phase content in $\mathrm{TiO}_{2}-2$ is higher than that in $\mathrm{TiO}_{2}-1$. It is well known that crystalline phase of $\mathrm{TiO}_{2}$ has an important influence on its photocatalytic activity. It has been reported that anatase phase is more effective than rutile phase in the photocatalytic decomposition of organic compounds and the improvement of anatase phase content can enhance the photocatalytic performance ${ }^{48-53}$. Therefore, the as-spun $\mathrm{TiO}_{2}-2$ should show better photocatalytic performance than $\mathrm{TiO}_{2}-1$.

\section{TABLE-1}

\section{PHASE CONTENT IN AS-SPUN $\mathrm{TiO}_{2}$ POWDER}

\begin{tabular}{ccc}
\hline Material & Anatase phase (\%) & Rutile phase (\%) \\
\hline $\mathrm{TiO}_{2}-1$ & 71.9 & 28.1 \\
$\mathrm{TiO}_{2}-2$ & 90.0 & 10.0 \\
\hline
\end{tabular}

The UV-visible absorbance of methylene blue with the time variation during $0.5 \mathrm{~h}$ adsorption-desorption equilibrium and subsequent photocatalytic process is shown in Fig. 3. As observed from Fig. $3 \mathrm{a}$ and c, the rapid decrease of the methylene blue absorbance indicates the good adsorption of methylene blue by both $\mathrm{TiO}_{2}-1$ and $\mathrm{TiO}_{2}-2$ and the equilibrium arrives in $0.5 \mathrm{~h}$. Furthermore, it can be obviously found that $\mathrm{TiO}_{2}-2$ shows better adsorption of methylene blue compared with $\mathrm{TiO}_{2}-1$. When $\mathrm{TiO}_{2}-1$ and $\mathrm{TiO}_{2}-2$ photocatalysts are used, the UVvisible absorption peak of methylene blue, related to the methylene blue concentration in the solution, becomes weak and shifts to short wavelength gradually with the increase of the time under UV light irradiation, as shown in Fig. $3 b$ and d. The peak shift should be due to the demethyleneation occurring at the catalyst surface ${ }^{54}$.

Fig. 4 shows the photocatalytic degradation rate of methylene blue with the time variation by $\mathrm{TiO}_{2}-1$ and $\mathrm{TiO}_{2}-2$. The normalized temporal concentration changes $\left(\mathrm{C} / \mathrm{C}_{0}\right)$ of methylene blue during the photocatalytic process are proportional to the normalized maximum absorbance $\left(\mathrm{A} / \mathrm{A}_{0}\right)$. It can be observed that $\mathrm{TiO}_{2}-2$ exhibits higher photocatalytic degradation rate $(95.6 \%)$ than $\mathrm{TiO}_{2}-1(77.9 \%)$ in $4 \mathrm{~h}$. The enhancement of the photocatalytic performance should be ascribed to the increase of anatase phase content and the adsorption of pollutants in $\mathrm{TiO}_{2}-2^{48-53,55-59}$. Fig. 5 displays the linear fitting using the pseudo-first-order kinetic equation to the experimental data for $\mathrm{TiO}_{2}-1$ and $\mathrm{TiO}_{2}-2$. The values of $\mathrm{k}$ can be obtained directly from the fitted straight-line plots of $\ln \left(\mathrm{C}_{\mathrm{i}} / \mathrm{C}_{0}\right)$ versus
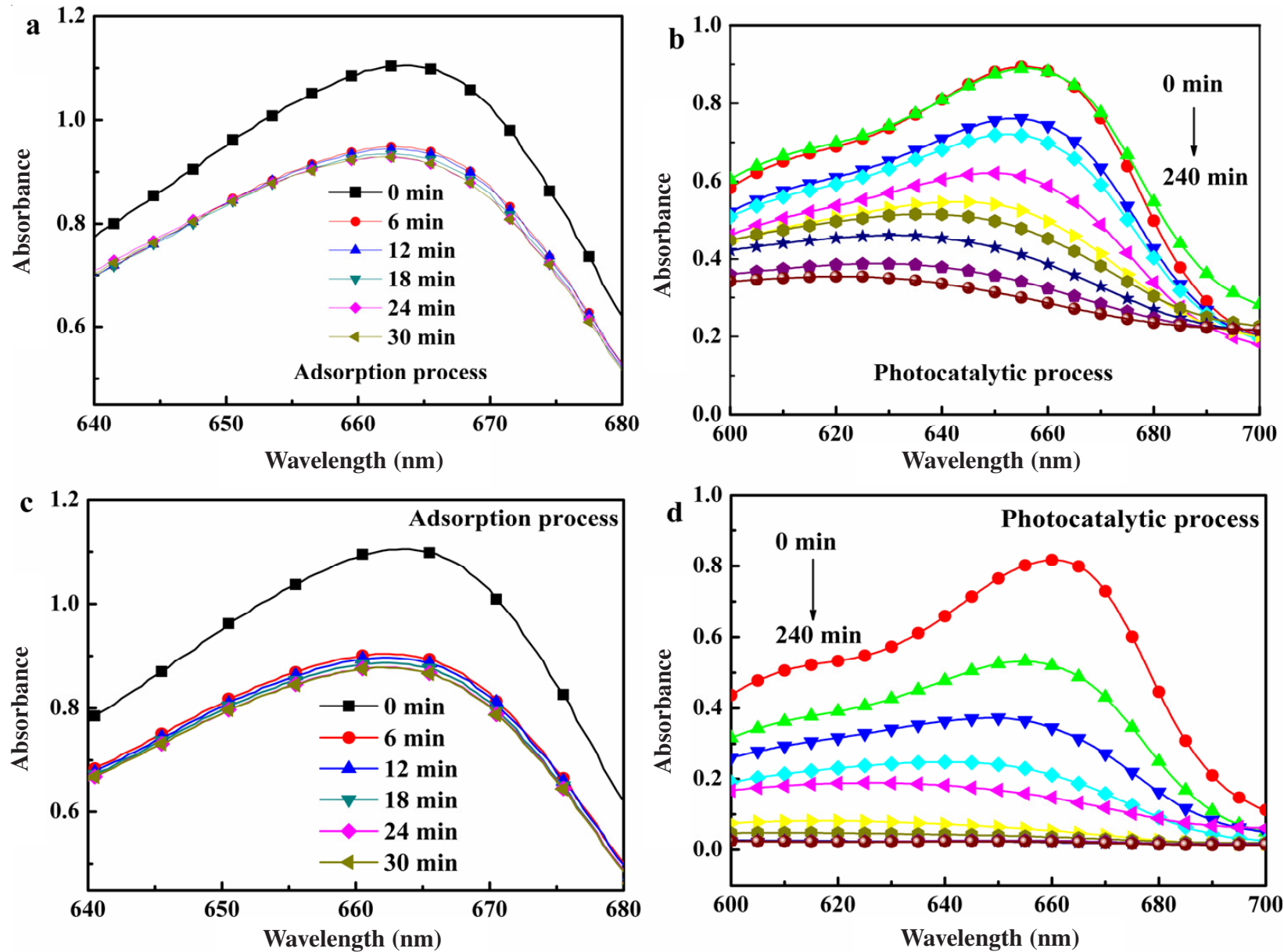

Fig. 3. UV-visible absorbance of methylene blue with the time variation during $0.5 \mathrm{~h}$ adsorption-desorption equilibrium and subsequent photocatalytic process: (a) and (b) $\mathrm{TiO}_{2}-1$, (c) and (d) $\mathrm{TiO}_{2}-2$ 
reaction time and follow the order: $\mathrm{TiO}_{2}-2\left(0.01772 \mathrm{~min}^{-1}\right)>$ $\mathrm{TiO}_{2}-1\left(0.00503 \mathrm{~min}^{-1}\right)$. $\mathrm{TiO}_{2}-2$ exhibits better photocatalytic activity with a rate constant much high than that of $\mathrm{TiO}_{2}-1$ under UV irradiation.

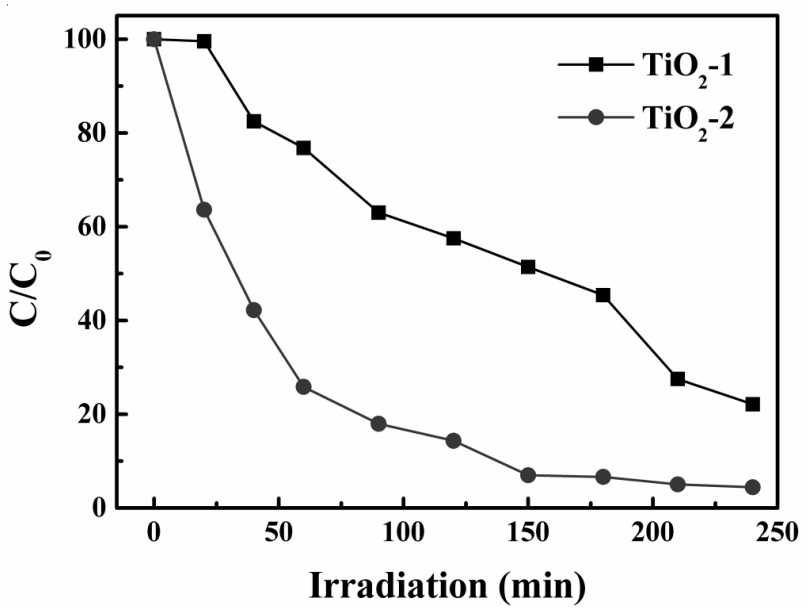

Fig. 4. Photocatalytic degradation of methylene blue by $\mathrm{TiO}_{2}-1$ and $\mathrm{TiO}_{2}$ 2 under UV irradiation. The concentrations of methylene blue and the photocatalyst are $5 \mathrm{mg} \mathrm{L}^{-1}$ and $2 \mathrm{~g} \mathrm{~L}^{-1}$, respectively

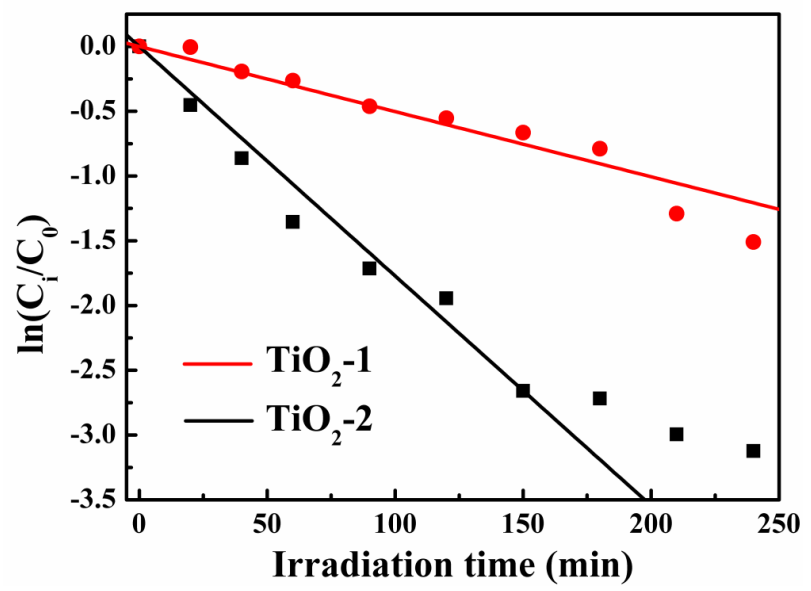

Fig. 5. Photocatalytic reaction kinetics of methylene blue with reaction time

\section{Conclusion}

$\mathrm{TiO}_{2}$ nanostructures were successfully synthesized via electrospinning technique and their photocatalytic performance in the degradation of methylene blue was investigated. The experimental results indicate that

(i) The introduction of urea in the precursor solution does not alter the composition of as-prepared $\mathrm{TiO}_{2}$ but changes the structure from rods to microspheres and increases the anatase phase content.

(ii) The surface of $\mathrm{TiO}_{2}$ microspheres is assembled by large quantities of $\mathrm{TiO}_{2}$ nanoparticles, resulting in a porous structure. Such a structure facilitates the adsorption of more pollutants.

(iii) $\mathrm{The} \mathrm{TiO}_{2}$ microspheres exhibit an excellent photocatalytic performance with a maximum degradation rate of $95.6 \%$, much higher than that for $\mathrm{TiO}_{2}$ rods $(77.9 \%)$; (iv) Electrospun $\mathrm{TiO}_{2}$ microspheres should be a promising photocatalyst for treating dye wastewater.

\section{ACKNOWLEDGEMENTS}

Financial support from Department of Education of Fujian Province (No. JB12072) is gratefully acknowledged.

\section{REFERENCES}

1. N. Murakami, Y.C. Fujisawa, T. Tsubota and T. Ohno, Appl. Catal. B, 92, 56 (2009)

2. X.J. Liu, L.K. Pan, T. Lv, Z. Sun and C.Q. Sun, RSC Adv., 2, 3823 (2012).

3. Z.G. Xiong, H.Q. Dou, J.H. Pan, J.Z. Ma, C. Xu and X.S. Zhao, Cryst. Eng. Comm., 12, 3455 (2010).

4. Q.J. Xiang, J.G. Yu and M. Jaroniec, Nanoscale, 3, 3670 (2011).

5. S.B. Rawal, A.K. Chakraborty, Y.J. Kim, H.J. Kim and W.I. Lee, RSC Adv., 2, 622 (2012).

6. M. Hirano and K. Matsushima, J. Nanosci. Nanotechnol., 6, 762 (2006).

7. T. Maiyalagan, B. Viswanathan and U.V. Varadaraju, J. Nanosci. Nanotechnol., 6, 2067 (2006).

8. W. Ho and J. C. Yu, J. Mol. Catal. A, 247, 268 (2006).

9. G.K. Mor, K. Shankar, M. Paulose, O.K. Varghese and C.A. Grimes, Nano Lett., 6, 215 (2006)

10. R. Thapa, S. Maiti, T.H. Rana, U.N. Maiti and K.K. Chattopadhyay, J. Mol. Catal. A, 363-364, 223 (2012).

11. P. Joshi, L.F. Zhang, D. Davoux, Z.T. Zhu, D. Galipeau, H. Fong and Q.G. Qiao, Energy Environ. Sci., 3, 1507 (2010).

12. M. Saif, S.M.K. Aboul-Fotouh, S.A. El-Molla, M.M. Ibrahim and L.F.M. Ismail, J. Nanopart. Res., 14, 1227 (2012).

13. H.B. Wang, S.L. Zhang, M.H. Liu, T.C. Liu and M. Yang, Asian J. Chem., 25, 1505 (2013).

14. H. Liu, Y.G. Liang, H.J. Hu and M.Y. Wang, Solid State Sci., 11, 1655 (2009).

15. Y.X. Tang, P.X. Wee, Y.K. Lai, X.P. Wang, D.G. Gong, P.D. Kanhere, T.T. Lim, Z.L. Dong and Z. Chen, J. Phys. Chem., 116, 2772 (2012).

16. X. Chen and S.S. Mao, Chem. Rev., 107, 2891 (2007).

17. D.A. Wang, L.F. Liu, F.X. Zhang, K. Tao, E. Pippel and K. Domen, Nano Lett., 11, 3649 (2011).

18. H. Robert, S.S. Felix, S. Jarno, T. Stefan, Y.Y. Song, J. Kunze, V.P. Lehto and P. Schmuki, Angew. Chem. Int. Ed., 48, 7236 (2009).

19. V. Etacheri, M.K. Seery, S.J. Hinder and S.C. Pillai, Adv. Funct. Mater., 21, 3744 (2011).

20. Y.W.L. Lim, Y.X. Tang, Y.H. Cheng and Z. Chen, Nanoscale, 2, 2751 (2010).

21. Z.F. Bian, J.A. Zhu, F.L. Cao, Y.N. Huo, Y.F. Lu and H.X. Li, Chem. Commun., 46, 8451 (2010).

22. Y.K. Lai, X.F. Gao, H.F. Zhuang, J.Y. Huang, C.J. Lin and L. Jiang, Adv. Mater, 21, 3799 (2009).

23. G.K. Mor, O.K. Varghese, M. Paulose, K. Shankar and C.A. Grimes, Sol. Energy Mater. Sol. Cells, 90, 2011 (2006).

24. A. Ghicov and P. Schmuki, Chem. Commun., 2791 (2009).

25. T. Kasuga, M. Hiramatsu, A. Hoson, T. Sekino and K. Niihara, Langmuir, 14, 3160 (1998).

26. D.V. Bavykin, J.M. Friedrich and F.C. Walsh, Adv. Mater, 18, 2807 (2006).

27. D.J. Yang, H.W. Liu, Z.F. Zheng, Y. Yuan, J.C. Zhao, E.R. Waclawik, X.B. Ke and H.Y. Zhu, J. Am. Chem. Soc., 131, 17885 (2009).

28. C. Zurmühl, R. Popescu, D. Gerthsen and C. Feldmann, Solid State Sci., 13, 1505 (2011).

29. A. Naldoni, C.L. Bianchi, C. Pirola and K.S. Suslick, Ultrason. Sonochem., 20, 445 (2013).

30. J.N. Liu, G.W. Zhang, W. Ao, K. Yang, S.X. Peng and M.G. Christel, Appl. Surf. Sci., 258, 8083 (2012).

31. C. Dwivedi, N. Raje, J. Nuwad, M. Kumar and P.N. Bajaj, Chem. Eng. J., 193-194, 178 (2012).

32. W.E. Teo and S. Ramakrishna, Nanotechnol., 17, 89 (2006).

33. H.R. Jung and W.J. Lee, J. Electroanal. Chem., 662, 334 (2011).

34. G. Zhu, L.K. Pan, J. Yang, X.J. Liu, H.C. Sun and Z. Sun, J. Mater. Chem., 22, 24326 (2012).

35. S.H. Park, D.H. Won, H.J. Choi, W.P. Hwang, S.I. Jang, J.H. Kim, S.H. Jeong, J.U. Kim, J.K. Lee and M.R. Kim, Sol. Energy Mater. Sol. Cells, 95, 296 (2011).

36. K. Miettunen, I. Asghar, X.L. Ruan, J. Halme, T. Saukkonen and P. Lund, J. Electroanal. Chem., 653, 93 (2011). 
37. T.Y. Zhao, Z.Y. Liu, K. Nakata, S. Nishimoto, T. Murakami, Y. Zhao, L. Jiang and A. Fujishima, J. Mater. Chem., 20, 5095 (2010).

38. D.W. Gao, Q.Q Wang, H. Qiao, Y.B. Cai, F.L. Huang and Q.F. Wei, J. Eng. Fiber. Fabr., 7, 94 (2012).

39. S.Y. Yang, P.N. Zhu, A.S. Nair and S. Ramakrishna, J. Mater. Chem., 21, 6541 (2011)

40. Y.G. Guo, L.J. Wan and C.L. Bai, J. Phys. Chem. B, 107, 5441 (2003).

41. X. Quan, S.G. Yang, X.L. Ruan and H.M. Zhao, Environ. Sci. Technol., 39, 3770 (2005).

42. A. Ghicov, J.M. Macak, H. Tsuchiya, J. Kunze, V. Haeublein, L. Frey and Pa. Schmuki, Nano Lett., 6, 1080 (2006).

43. H.G. Yu, J.G. Yu, B. Cheng and S.W. Liu, Nanotechnol., 18, 065604 (2007).

44. R.A. Caruso, M. Antonietti, M. Giersig, H.P. Hentze and J.G. Jia, Chem. Mater., 13, 1114 (2001).

45. Y. Zhang, J.C. Crittenden, D.W. Hand and D.L. Perram, Environ. Sci. Technol., 28, 435 (1994).

46. Z.B. Zhang, C.C. Wang, R. Zakaria and J. Y. Ying, J. Phys. Chem. B, 102, $10871(1998)$

47. S. Zhou, J. Lv, L.K. Guo, G.Q. Xu, D.M. Wang, Z.X. Zheng and Y.C. Wu, Appl. Surf. Sci., 258, 6136 (2012).
48. X.W. Zhang, S.Y. Xu and G.R. Han, Mater Lett., 63, 1761 (2009).

49. W.M. Xi and S. Geissen, Water Res., 35, 1256 (2001).

50. M. Inagaki, R. Nonaka, B. Tryba and A.W. Morawski, Chemosphere, 64, 437 (2006)

51. S.J. Doh, C. Kim, S.e G. Lee, S.J. Lee and H. Kim, J. Hazard. Mater, 154, 118 (2008).

52. H.P. Li, W. Zhang and W. Pan, J. Am. Ceram. Soc., 94, 3184 (2011).

53. A.L. Castro, M.R. Nunes, A.P. Carvalho, F.M. Costa and M.H. Florencio, Solid State Sci., 10, 602 (2008).

54. L. Rizzo, J. Koch, V. Belgiorno and M.A. Anderson, Desalination, 211, 1 (2007).

55. B. Tryba, A.W. Morawski and M. Inagaki, Appl. Catal. B, 41, 427 (2003).

56. L.X. Zhang, P. Liu and Z.X. Su, J. Mol. Catal. A: Chem., 248, 189 (2006).

57. K.K. Akurati, A. Vital, G. Fortunato, R. Hany, F. Nueesch and T. Graule, Solid State Sci., 9, 247 (2007).

58. M. Hamadanian, A. Akbari and V. Jabbari, Fiber. Polym., 12, 880 (2011).

59. X. J. Liu, L. K. Pan, T. Lv, G. Zhu, T. Lu, Z. Sun and C. Q. Sun, RSC Adv., 1, 1245 (2011). 